\title{
KHOANH VÙNG NGUY CƠ NGẬP LỤT DO ẢNH HƯỞNG MƯA KÉO DÀI Ở THỦ ĐÔ HÀ NỘI BẰNG TỦ LIỆ VIỄN THÁM VÀ GIS
}

\author{
ThS. HOÀNG THI! THU HÀ, TS. PHẠM MINH HẢl, CN. TRẦN TH!̣ HÔNG HÀ \\ Viện Khoa học Đo đạc và Bản đồ
}

\section{Giới thiệu chung}

1 gập lụt luôn là mối hiểm họa đặc biệt với các vùng đô thị, gây nên nhiều thiệt hại về nhà cửa, các công trình hạ tầng công cộng và đặc biệt ảnh hưởng đến cuộc sống của con người. Những năm gần đây, do ảnh hưởng của hiện tượng El Nino và La Nina, những trận bão biển và mưa lớn xảy ra ngày càng nhiều. Bên cạnh đó, trong quá trình đô thị hoá nhanh, hạ tầng đô thị ngày càng được bê tông hoá làm giảm bề mặt thấm lọc tự nhiên. Do vậy khi mưa lớn không có nơi thoát nước, hệ thống quá tải tình trạng ngập lụt xảy ra thường xuyên hơn.

Gần đây, thành phố Hà Nội hứng chịu tình trạng ngập lụt mỗi khi mưa lớn kéo dài. Địa hình Hà nội thấp dần theo hướng từ Bắc xuống Nam và từ Tây sang Đông với độ cao trung bình từ 5 đến $20 \mathrm{~m}$ so với mực nước biển, đồng bằng chiếm $3 / 4$ diện tích tự nhiên. Hà Nội cũng là một thành phố đặc biệt nhiều đầm hồ, dấu vết còn lại của các dòng sông cổ. Do quá trình đô thị hoá mạnh mẽ, nhiều hồ ao tự nhiên bị san lấp xây dựng nhà ở, công trình. Các sông Tô Lịch, Kim Ngưu, Lừ, Sét ngoài vai trò tiêu thoát nước thải chính của thành phố còn phải nhận thêm một phần rác thải của người dân và chất thải công nghiệp. Từ cuối thập niên 1990 và thập niên 2000, sự phát triển về kinh tế dẫn đến các khu vực ngoại ô Hà Nội nhanh chóng được đô thị hóa. Nhiều đường giao thông chính của Hà Nội được mở rộng. Do thiếu quy hoạch đồng bộ trong vấn đề thoát nước, nên các khu đô thị mới này cũng gặp nhiều vấn đề về tình trạng ngập úng mỗi khi mưa lớn.

Viễn thám và hệ thống thông tin địa lý là một trong rất nhiều công cụ hiện có để quản lý thiên tai một cách chuyên nghiệp mà ngày nay đã mang lại kế hoạch hiệu quả. Mục đích của bài báo là phân tích hiện trạng ngập do mưa lớn gây ra ở Thủ đô Hà Nội với mốc là hai trận mưa lịch sử năm 2008 và 2013 nhằm khoanh vùng nguy cơ ngập lụt do ảnh hưởng mưa kéo dài ở thủ đô Hà Nội bằng tư liệu viễn thám và GIS. Nội dung của phương pháp luận là sử dụng ảnh vệ tinh để nhận dạng và trích lọc vùng ngập lụt do hiện tượng mưa lớn kéo dài.

\section{Khu vực nghiên cứu và dữ liệu đầu vào \\ Khu vực nghiên cứu được giới hạn trong khu vực nội thành Hà Nội.}

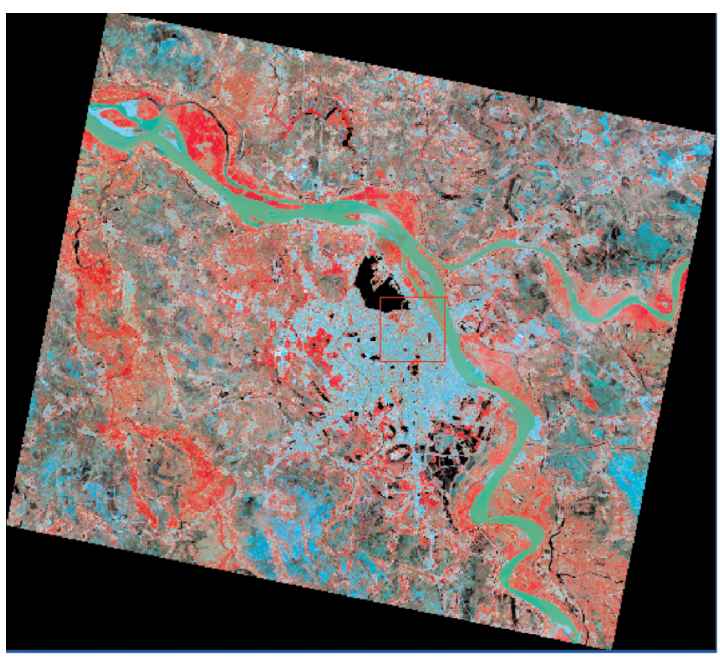

Hình 1: Khu vực nghiên cứu (Ảnh SPOT5 tổ hợp màu giả). 
Bài báo sử dụng dữ liệu ảnh đa phổ DMC L1R ở độ phân giải 32 mét chụp ngày 9 tháng 11 năm 2008. Ảnh được cung cấp bởi Viện Nghiên cứu và Đào tạo (UNITAR) của Liên Hiệp Quốc. Ảnh vệ tinh SPOT5 với độ phân giải $10 \mathrm{~m}$ khu vực Hà Nội. Dữ liệu địa hình, và lượng mưa tại thời điểm lụt tháng 11 năm 2008 và tháng 7 năm 2013 ở khu vực Hà Nội.

Với tổng lượng mưa của một số trạm trên địa bàn thành phố Hà nội qua thời điểm từ ngày $30 / 10$ đến ngày $02 / 11$ năm 2008 và thời điểm ngày $7 / 8$ đến ngày $9 / 8$ năm 2013 tại các trạm như sau:

Bảng 1: Bảng thống kê tổng lượng mưa tại các trạm quan trắc ở thời điểm 2008 và 2013

\begin{tabular}{|c|l|c|c|}
\hline STT & Tên trạm & $\begin{array}{c}\text { Năm 2008 } \\
(\mathrm{mm})\end{array}$ & $\begin{array}{c}\text { Năm 2013 } \\
(\mathrm{mm})\end{array}$ \\
\hline 1 & Láng & 563.2 & 127 \\
\hline 2 & Hà Đông & 812.9 & 102 \\
\hline 3 & Hà Nội & 541 & 156.6 \\
\hline 4 & Thượng Cát & 593.2 & 122 \\
\hline 5 & Đông Anh & 566 & 115 \\
\hline 6 & Thanh Trì & 499.9 & 156 \\
\hline
\end{tabular}

\section{Phương pháp tiến hành}

Ảnh vệ tinh SPOT5 được nắn chỉnh bằng thuật toán đa thức với 20 điểm khống chế. Dữ liệu ảnh đa phổ DMC L1R được xử lý về độ phân giải 10 mét của ảnh nền SPOT5. Sau đó, việc chiết tách thông tin khu vực ngập nước thời điểm tháng 11 năm 2008 được thực hiện bằng việc sử dụng phương pháp lấy ngưỡng (Thresold) ở băng NIR của ảnh đa phổ DMC L1R. Kết quả thu được được thể hiện trên hình 2.

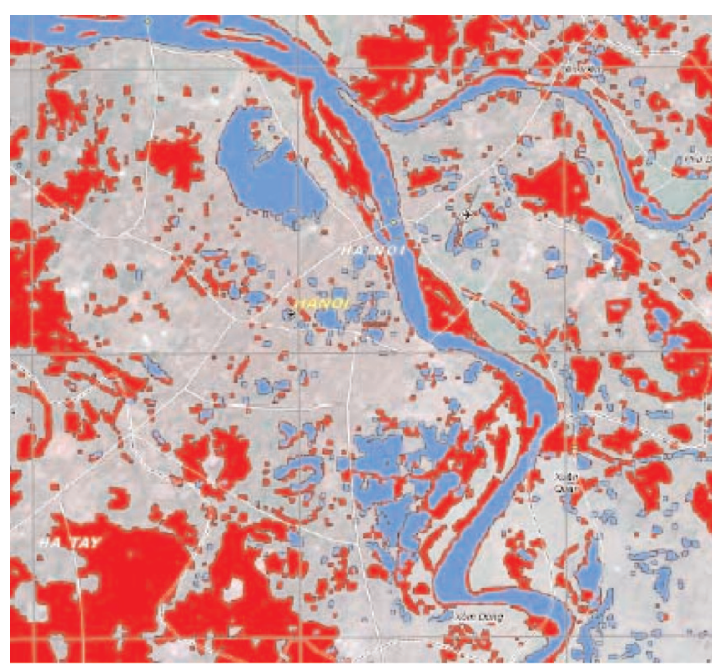

Khu vực nước

Hồ, ao

Hình 2: Khu vực ngập lụt thời điểm tháng 11 năm 2008

Khu vực ngập nước được chiết tách sau đó được chồng ghép lên ảnh vệ tinh nền SPOT5.

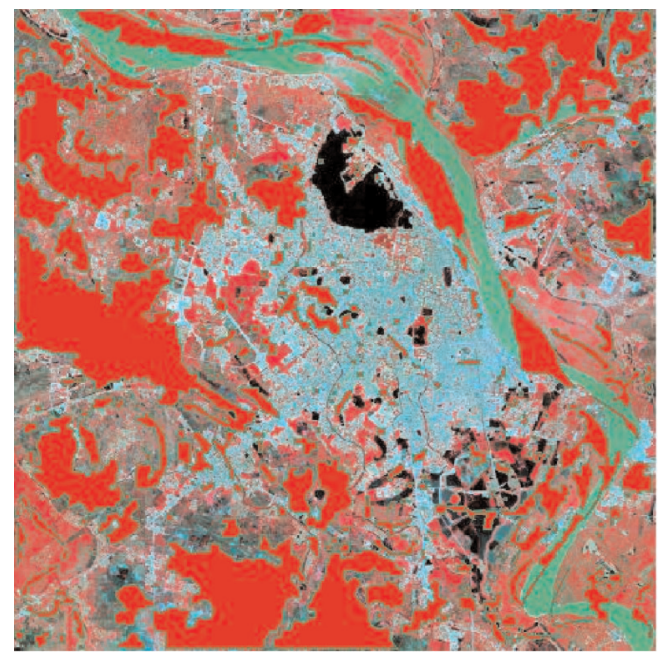

Sông, hồ, ao

Khu vực nước

Hình 3: Kết quả chồng ghép dũ liệu ngập nước thời điểm tháng 11 năm 2008 lên trên ảnh vệ tinh SPOT5 
Bên cạnh đó, nhóm nghiên cứu cũng sử dụng lớp dữ liệu vector đường giao thông để phục vụ phân tích ảnh hưởng của hiện tượng ngập úng của khu vực Hà Nội.

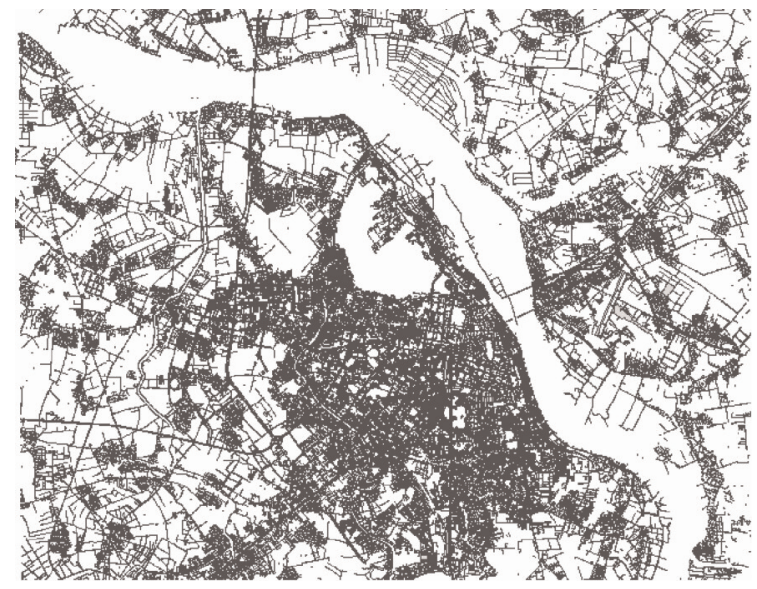

Hình 4: Mạng lưới giao thông khu vực Hà Nội

Mô hình số độ cao DEM được tạo lập từ bản đồ địa hình 1:10.000. Dựa vào dữ liệu DEM, tiến hành nội suy địa hình theo mô hình TIN (Triangulated Irregular Network). Từ mô hình số độ cao có thể tạo các hướng nhìn khác nhau, phân tích độ dốc, địa hình, thuỷ văn và mô phỏng khu vực ngập.

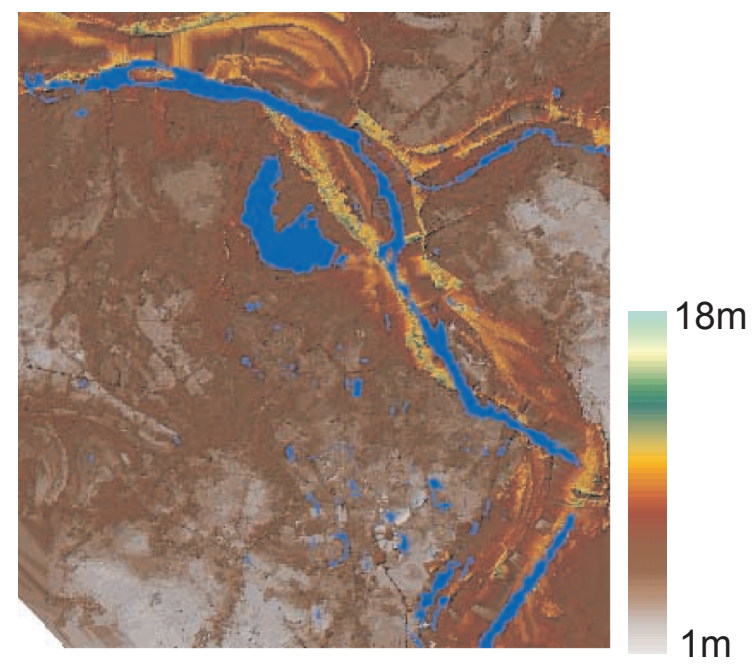

Hình 5: Mô hình số độ cao của khu vực Hà Nội
Do thiếu dữ liệu ảnh chụp khu vực Hà Nội ngập úng do ảnh hưởng trận mưa lớn tháng 7 năm 2013, nên nhóm nghiên cứu sử dụng phương pháp thu thập thông tin để thống kê các điểm ngập úng. Dữ liệu này được sử dụng kết hợp với dữ liệu ngập nước của thành phố Hà Nội tháng 11 năm 2008, thể hiện cùng với dữ liệu độ cao địa hình trên các phần mềm GIS để phân tích, chỉ ra những điểm ngập lụt, phạm vi ngập lụt, các tuyến đường ngập úng để từ đó cung cấp cho người sử dụng những thông tin về khu vực đô thị bị ảnh hưởng bởi mưa lớn. Phương pháp chồng ghép này giúp cho các cơ quan và người sử dụng biết được những vùng đã bị lụt xảy ra ở đâu, phạm vi ra sao và những đường giao thông nào đã bị ảnh hưởng.

\section{Kết quả nghiên cứu}

Để phục vụ công tác phân tích và đánh giá phạm vi ngập nước do ảnh hưởng mưa lớn khu vực Hà Nội, nhóm nghiên cứu tiến hành chồng các lớp dữ liệu. Hình 6 thể hiện mối tương quan giữa phạm vi chịu ảnh hưởng ngập nước, độ cao khu vực đô thị, và những tuyến đường bị ngập nước qua cả hai thời điểm. (Xem hình 6)

So với lượng mưa của trận mưa lịch sử tháng 11 năm 2008 ở khu vực Hà Nội, lượng mưa trận mưa tháng 7 năm 2013 chỉ bằng 1/5 và phạm vi ngập nước cũng ít hơn, nhưng cũng gây ngập úng trên diện rộng khu vực nội đô Hà Nội. Nhìn vào hình 6 , khu vực ngập lụt ở 2 thời điểm xảy ra phổ biến ở nơi có độ cao thấp nhất của Hà Nội từ 1 mét đến 3.8 mét. Điển hình đường Phạm Văn Đồng, Phạm Hùng, ngã tư Tây Sơn Thái Hà, Phạm Ngọc Thạch, Đại La, Huỳnh Thúc Kháng. So với vùng ven đô thì phạm vi chịu ảnh hưởng của khu vực nội thành ít hơn.

Để cung cấp cho người sử dụng hình ảnh về phạm vi khu vực chịu ảnh hưởng hiện tượng ngập úng, nhóm nghiên cứu đã 


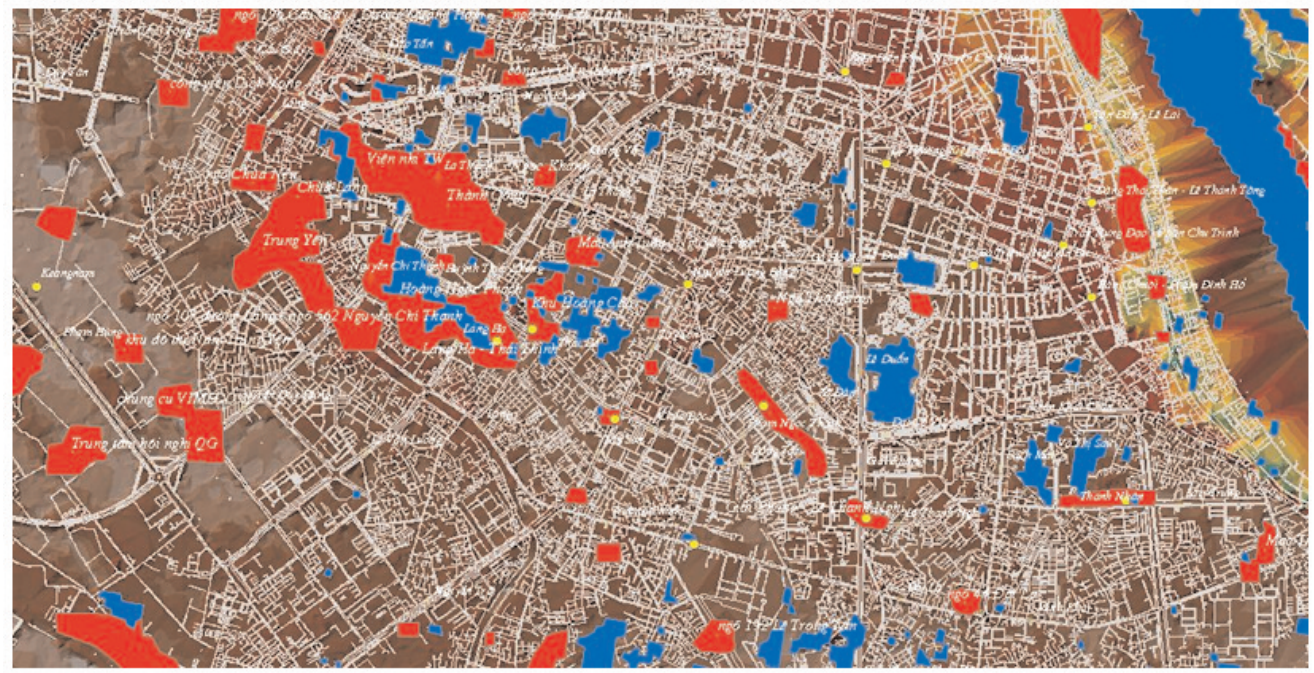

Sông, hồ, ao

Đường giao thông

Điểm ngập nước tháng 11 năm 2008

Điểm ngập nước tháng 7 năm 2013

Hình 6: Khoanh vùng ngập lụt ở Hà Nội sau trận mưa lớn kéo dài năm 2008 và 2013

tiến hành tổng hợp đánh giá các điểm cùng bị ngập nước trong cả hai thời điểm 2008 và 2013, kết hợp với mô hình số độ cao trên nền ảnh vệ tinh SPOT5 và phát triển mô hình 3D (Hình 7) mô tả các khu vực dễ bị ảnh hưởng bởi hiện tượng ngập nước do ảnh hưởng của mưa lớn ở khu vực nội đô Hà Nội. Căn cứ vào kết quả nghiên cứu, những khu vực có nguy cơ bị ngập lụt khi mưa lớn ở khu vực Hà Nội đã được xây dựng để có biện pháp chuẩn bị phòng tránh kịp thời, giảm thiểu ảnh hưởng của hiện tượng ngập nước tới đời sống xã hội. (Xem hinh 7)

\section{Kết luận}

Nghiên cứu có tính thực tiễn cao khi kết hợp dữ liệu viễn thám và GIS trong theo dõi phạm vi ngập nước khu vực đô thị do ảnh hưởng của mưa lớn. Trong những năm gần đây, hiện tượng ngập nước ở thủ đô Hà Nội xảy ra thường xuyên hơn. Kết quả này giúp cho người sử dụng dữ liệu có thể hình dung khu vực ngập nước xảy ra ở đâu, liên quan đến tuyến đến đường giao thông nào, ảnh hưởng đến khu vực đô thị ra sao. Nhóm nghiên cứu đã tiến hành công tác xử lý ảnh để nhận dạng được khu vực ngập nước qua ở 2 thời điểm tháng 11 năm 2008, và thu thập các điểm ngập úng do mưa lớn gây ra ở khu vực Hà Nội tháng 11 năm 2013. Việc chồng ghép dữ liệu ngập nước lên dữ liệu DEM và ảnh vệ tinh khu vực Hà Nội đóng vai trò hiệu quả khi phân tích mục tiêu bài báo. Nhóm nghiên cứu phân tích được sự thay đổi của khu vực đô thị chịu ảnh hưởng của hiện tượng úng ngập qua thời gian, đặc biệt là khu vực đô thị chịu ảnh hưởng của hiện tượng úng ngập ở cả 2 thời điểm 2008 và 2013 để làm cơ sở đề xuất mô hình 3D mô tả các khu vực dễ bị ảnh hưởng bởi hiện tượng ngập nước. Kết quả nghiên cứu được hy vọng là nguồn tài liệu tham khảo có giá trị, trợ giúp hiệu quả những nhà quản lý khi ra những quyết định liên quan đến quy hoạch và kế hoạch sử dụng đất đô thị.. 


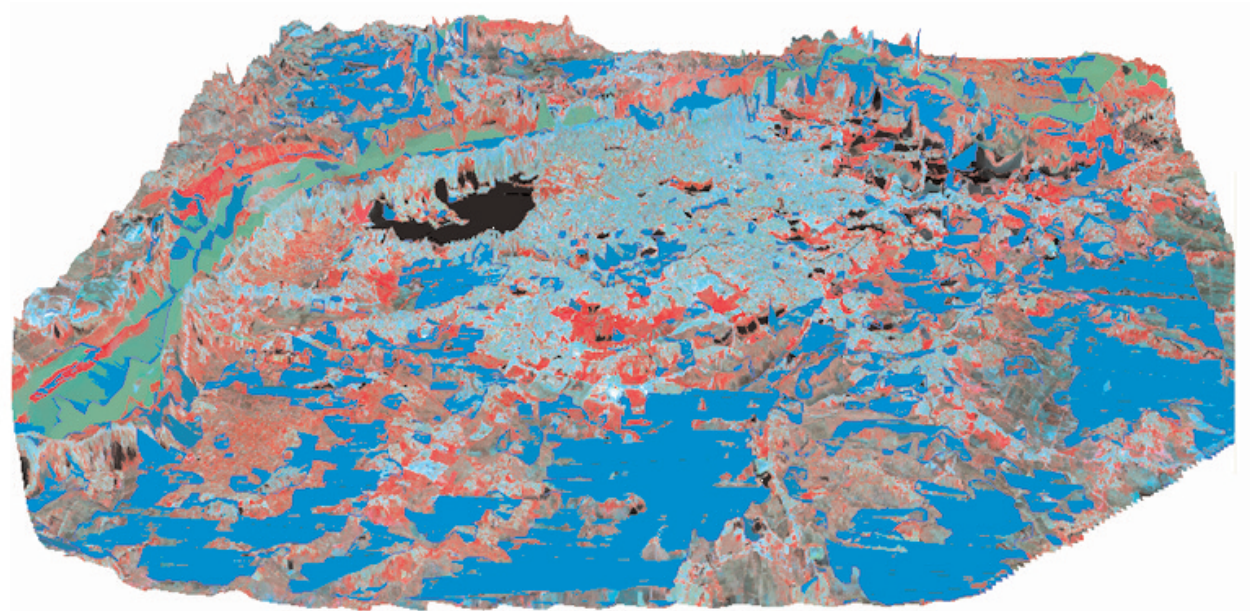

Khu vực dễ bị ảnh hưởng bởi hiện tượng ngập nước

Sông, hồ, ao

Các đối tượng khác

Hình 7: Mô hình 3D mô tả các khu vực dễ bị ảnh hưởng bởi hiện tượng ngập nước

Tài liệu tham khảo

[1]. Pham Viet Hoa, Use of Remote Sensing and GIS Technology for Monitoring and Assessment of Flooding Status at the Coastal Zone in the Central Part of Vietnam, http://www.fig.net/pub/jakarta/papers/ts 19/t s 19 4_pham.pdf

[2]. Shailesh Nayak (2008),Sisi Zlatanova, Remote Sensing and GIS Technologies for Monitoring and Prediction of Disasters. $O$

\section{Summary}

Localizing the risk of flooding due to prolonged heavy rain in Hanoi by using remote sensing and GIS data

\section{MSc. Hoang Thi Thu Ha, Dr. Pham Minh Hai, BSc. Tran Thi Hong Ha}

Flooding is always a severe thread to urban areas, causing extensive damage to houses, buildings, public infrastructure and human life. In recent years, due to the effects of El Nino and La Nina, more and more ocean storms and heavy rain have been occurring. Besides, in the process of urbanization, the growing use of concrete to build urban infrastructure has decreased the natural surface infiltration. Consequently, when heavy rain happens, flooding occurs more frequently because of the overloaded drainage systems. Recently, Ha Noi has suffered heavy flooding after prolonged rain. The purpose of this article is to analyze flood situation due to heavy rain in Ha Noi (in 2008 and 2013) in order to localize the risk of flooding in Ha Noi by using remote sensing and GIS data. The content of the methodology is to use satellite images to identify and extract flooded areas because of the prolonged periods of heavy rainfall and then use some analytical methods to implement the subject's target. $O$

\section{Ngày nhận bài: 30/8/2013.}

